\title{
Isolation, culture, and characterisation of human macular inner choroidal microvascular endothelial cells
}

\author{
A C Browning, T Gray, W M Amoaku
}

Br J Ophthalmol 2005;89:1343-1347. doi: 10.1136/bjo.2004.063602

Aim: To develop a method for the reliable isolation of adult human macular inner choroidal endothelial cells (ICECs) and to subsequently characterise them for their expression of a range of endothelial cell associated surface markers.

Method: Human ICECs were isolated after manual dissection of maculas from fresh human posterior segments. Following enzyme digestion to form a single cell suspension, the ICECs were isolated using anti-CD31 coated Dynabeads. The isolated cells were grown in culture and examined for typical endothelial cell morphology, surface expression of vWf, CD 31, CD 105, VEGF receptors 1 and 2, and expression of Eselectin after stimulation with TNF- $\alpha$. The cells were also examined for their ability to form fenestrations and capillarylike tubes in Matrigel.

Results: The method enabled the rapid isolation of viable cells that demonstrated typical endothelial cobblestone morphology in culture. The cells stained positive for CD31, vWf, CD105, VEGF receptors 1 and 2, and E-selectin (after stimulation with TNF- $\alpha$ ). The cells stained negative for $\alpha$ smooth muscle actin and fibroblast surface protein. The cells also developed fenestrations when cultured on fibronectin coated plates and formed capillary-like tubes structures when cultured on Matrigel.

Conclusions: This technique isolates cells from the human macular inner choroid that display features consistent with vascular endothelial cells. These cells could subsequently be used to further the understanding of the pathophysiological mechanisms of diseases of the inner choroid, such as choroidal neovascularisation.

$\mathrm{T}$ he neovascular or "wet" form of age related macular degeneration (ARMD) is characterised by the growth of new blood vessels from the inner choroid (including the choriocapillaris). ${ }^{1-3}$ While the initiating event causing wet ARMD is unknown, it is widely acknowledged that the microvascular endothelial cell plays a pivotal part in the disease process.

It is widely accepted however, that endothelial cells derived from different species, vascular organs and from within different vascular beds within those organs display different morphological, biochemical and phenotypical heterogeneity. ${ }^{4-15}$ This suggests that the use of bovine, umbilical vein, or heterogeneous mixtures of human choroidal endothelial cells to study the pathophysiological mechanisms of ARMD $^{16-19}$ may not be truly representative.

To understand the angiogenic mechanisms important in the development of ARMD, it would be advantageous to study the behaviour of endothelial cells derived from the site where the disease occurs - that is, within the inner choroid of the human macula. In this study, we describe a method that allows the reliable isolation and culture of human macular inner choroidal microvascular endothelial cells (ICECs).

\section{MATERIALS AND METHODS}

Isolation of macular inner choroidal endothelial cells Human posterior segments free of any known ocular disease were obtained from UK Transplant. The research had the approval of the local research ethics committee (Nottingham 2 LREC). After the iris had been removed, an $8 \mathrm{~mm}$ biopsy punch was positioned over the macula and pressure was applied, sufficient to penetrate the full thickness of the sclera. The macular sample was removed and transferred to a petri dish where the retina was discarded and retinal pigment epithelium (RPE) removed by gentle brushing with a sterile spatula and irrigation with sterile phosphate buffered saline (PBS). The choroid was then gently teased from the attached sclera and turned upside down. With the use of a dissecting microscope, the outer choroidal vessels along with adherent pigmented fibrous tissue were peeled off, leaving the relatively non-pigmented inner choroid and choriocapillaris/ Bruch's membrane complex. The tissue was cut into $1 \mathrm{~mm}$ pieces and washed three times in minimum essential medium (MEM) (Invitrogen Ltd, Paisley, UK) containing $30 \mathrm{mM}$ HEPES, $0.25 \mu \mathrm{g} / \mathrm{ml}$ amphotericin B, $100 \mu \mathrm{g} / \mathrm{ml}$ streptomycin, $50 \mu \mathrm{g} / \mathrm{ml}$ kanamycin, and $30 \mu \mathrm{g} / \mathrm{ml}$ penicillin (isolation medium). The pieces were incubated in $0.1 \%$ collagenase I (Sigma-Aldrich) in MEM for 2 hours at $37^{\circ} \mathrm{C}$, with frequent agitatation. The collagenase was neutralised with MEM containing 10\% fetal calf serum (Invitrogen Ltd, Paisley, UK). and the mixture filtered through sterile $40 \mu \mathrm{m}$ and $20 \mu \mathrm{m}$ filters (Millipore Ltd, Watford, UK). The eluate was centrifuged $(75 \mathrm{~g})$ and washed three times in isolation medium, and resuspended in $1 \mathrm{ml}$ of PBS/0.1\%BSA. The endothelial cells were then isolated as in the manufacturer's instructions (Dynal Ltd, Wirral, UK). The Dynabeads were resuspended in endothelial growth medium (EGM2-MV with hydrocortisone omitted, Cambrex Biosciences, Wokingham, Berks, UK) and seeded onto fibronectin coated $35 \mathrm{~mm}$ culture dishes (Beckton Dickinson, Oxford, UK). The cells were incubated at $37^{\circ} \mathrm{C}$ in a humidified atmosphere of $5 \%$ $\mathrm{CO}_{2}$ and the medium changed every 2 days. Cells were passaged with $0.025 \%$ trypsin and $0.01 \%$ EDTA in sterile PBS. All reagents were from Sigma-Aldrich, Poole, Dorset, UK unless otherwise specified.

\section{Endothelial cell characterisation}

After growing the cells (passage 1) on $1 \%$ gelatin coated glass cover slips (VWR Ltd, Poole, UK) and fixing them in ice cold

\footnotetext{
Abbreviations: $\alpha-S M A, \alpha$ smooth muscle actin; ARMD, age related macular degeneration; EGM, endothelial growth medium; FITC, fluorescein isothiocyanate; ICECs, inner choroidal endothelial cells; MEM, minimum essential medium; PBS, phosphate buffered saline; RPE, retinal pigment epithelium; TEM, transmission electron microscopy; VEGF, vascular endothelial growth factor
} 


\begin{tabular}{|llll|}
\hline \multicolumn{2}{l}{ Table 1} & Primary antibodies used in study & \\
\hline Epitope & Class & Dilution & Source \\
\hline CD31 & murine lgG1 & $1: 20$ & Dako, Cambridgeshire, UK \\
CD105 & murine lgM & $1: 20$ & Novo Castra Laboratories, \\
& & Peterborough, UK \\
vWf & rabbit immunoglobulin fraction $1: 200$ & Dako, Cambridgeshire, UK \\
Receptor 1 VEGF & murine lgG1 & $1: 100$ & Sigma-Aldrich, Poole, UK \\
Receptor 2 VEGF & murine lgG1 & $1: 800$ & Sigma-Aldrich, Pool, UK \\
$\alpha$-SMA & murine lgG1 & $1: 50$ & Dako, Cambridgeshire, UK \\
Fibroblast surface protein & murine lgG1 & $1: 200$ & Dako, Cambridgeshire, UK \\
E-selectin/CD62E & murine lgG1 & $1: 20$ & Serotec, Oxford, UK \\
Negative & murine lgG1 & Dako, Cambridgeshire, UK \\
\hline & & & \\
\hline
\end{tabular}

methanol at $-20^{\circ} \mathrm{C}$ for 20 minutes, a standard two stage immunofluorescence technique was applied, ${ }^{20}$ using primary antibodies detailed in table 1. (E-selectin expression was examined after exposure to TNF- $\alpha(100 \mathrm{pg} / \mathrm{ml})$ ( R and D Systems, Abingdon, UK) or PBS for 4 hours before fixation.) The secondary antibody used was rabbit anti-mouse $\mathrm{F}\left(\mathrm{ab}^{\prime}\right)_{2}$ fragment, fluorescein isothiocyanate (FITC) conjugated ( $1: 20$ dilution) (Dako, Ely, Cambridgeshire, UK) in all cases except $v W f$, for which swine anti-rabbit $\mathrm{F}\left(\mathrm{ab}^{\prime}\right)_{2}$ fragment FITC conjugate was used (1:20 dilution) (Dako). The slides were mounted in glycerol containing 2.5\% $1-4$ diazabicyclo [2, 2, 2]-octane (DABCO) (Sigma-Aldrich) and observed by confocal fluorescence microscopy (Leica TCS40D, Leica, Milton Keynes, UK). Frozen sections of fresh human placenta were used as a positive control for the vascular endothelial growth factor (VEGF) receptor antibodies, while HUVEC cells were used as a positive control for all other antibodies except for anti- $\alpha$ smooth muscle actin (anti- $\alpha$-SMA) and antihuman fibroblast, for which human retinal pigment epithelial cells and human Tenon's capsule fibroblasts were used respectively.

\section{Transmission electron microscopy (TEM)}

Isolated cells were grown to confluence on $35 \mathrm{~mm}$ fibronectin coated culture dishes (Becton Dickinson, Oxford, UK) The
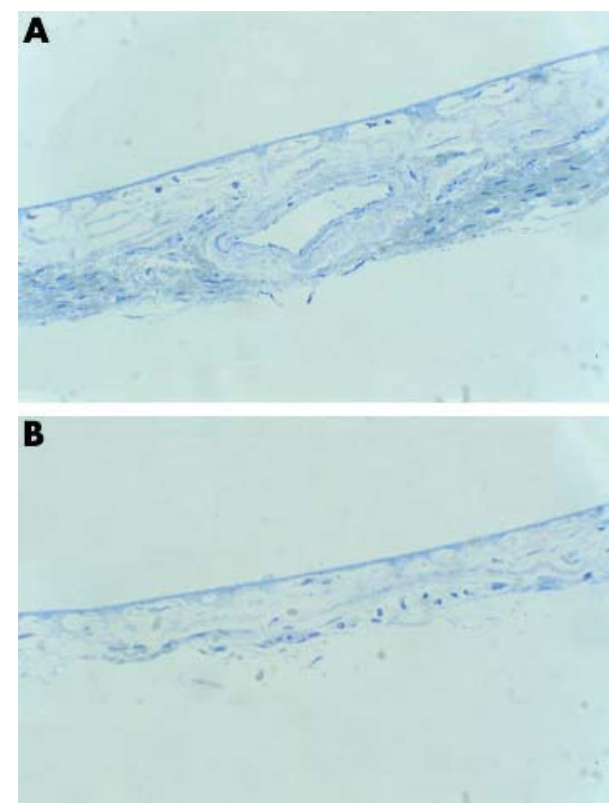

Figure 1 Histological section of human submacular choroid stained with toludine blue (A) before and (B) after removal of the outer choroidal vessels. (B) Shows the residual choriocapillaris and inner choroidal vessels attached to Bruch's membrane.

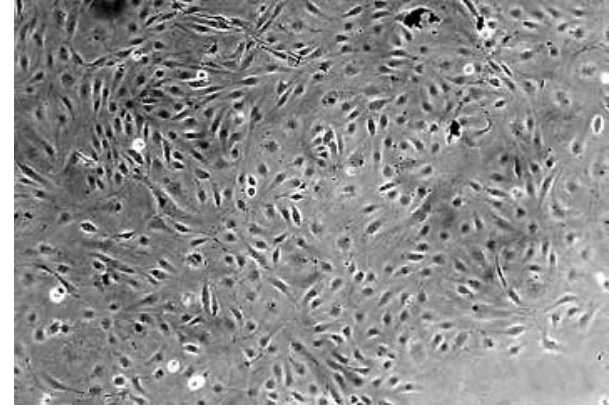

Figure 2 Phase contrast photomicrograph of confluent primary culture of ICECs demonstrating a typical cobblestone appearance $(20 \times$ original magnification).

cells were fixed by immersion in $2.5 \%$ glutaraldehyde (in $0.1 \mathrm{M}$ cacodylate buffer, $\mathrm{pH}$ 7.4) for 16-24 hours and processed for TEM as previously described..$^{212}$

\section{In vitro tube formation}

A 1:1 mixture of chilled Matrigel (Beckton Dickinson Biosciences, Oxford, UK) and endothelial growth medium (EGM2-MV) was dispensed into pre-chilled wells of a 96 well plate. The Matrigel was allowed to solidify at $37^{\circ} \mathrm{C}$ for 30 minutes before isolated cells suspended in endothelial growth medium were seeded at a density of $4.8 \times 10^{4}$ per well. The wells were observed hourly for the formation of tubes. For TEM, the endothelial growth medium was removed and replaced by $2.5 \%$ glutaraldehyde (in $0.1 \mathrm{M}$ cacodylate buffer, $\mathrm{pH}$ 7.4) for $16-24$ hours at $37^{\circ} \mathrm{C}$. The fixed Matrigel was then gently removed from the well and processed as described previously. ${ }^{21} 22$

\section{RESULTS}

Human posterior segments of six donors were obtained. The age of the donors (years) and the time from death to endothelial cell isolation (hours) were: 45 (52), 76 (42), 70 (43), $37(60), 83(60)$, and 56 (60).

Light microscopy after dissection showed the sample to comprise Bruch's membrane along with adherent choriocapillary and inner choroidal vessels (fig $\mathrm{IA}$ and B).

After isolation, the cells from all donors grew with a cobblestone morphology typical of endothelial cells (fig 2). The isolated cells showed a positive expression for vWf (fig 3A), CD31 (fig 3B), CDI05 (fig 3C), VEGF receptor 1 (fig 3D), and receptor 2 (fig 3E), E-selectin before and after stimulation with TNF $\alpha(100 \mathrm{pg} / \mathrm{ml}$ ) (fig $3 \mathrm{~F}$ and $\mathrm{G})$. The cells were negative for mouse anti-rat isotype control (fig $3 \mathrm{H}$ ), $\alpha$ SMA (fig 3I) and anti-fibroblast surface protein (fig 3J). Human RPE cells and Tenon's capsule fibroblasts showed expression of $\alpha$-SMA (fig $3 \mathrm{~K}$ ) and fibroblast surface protein (fig 3L), respectively. 

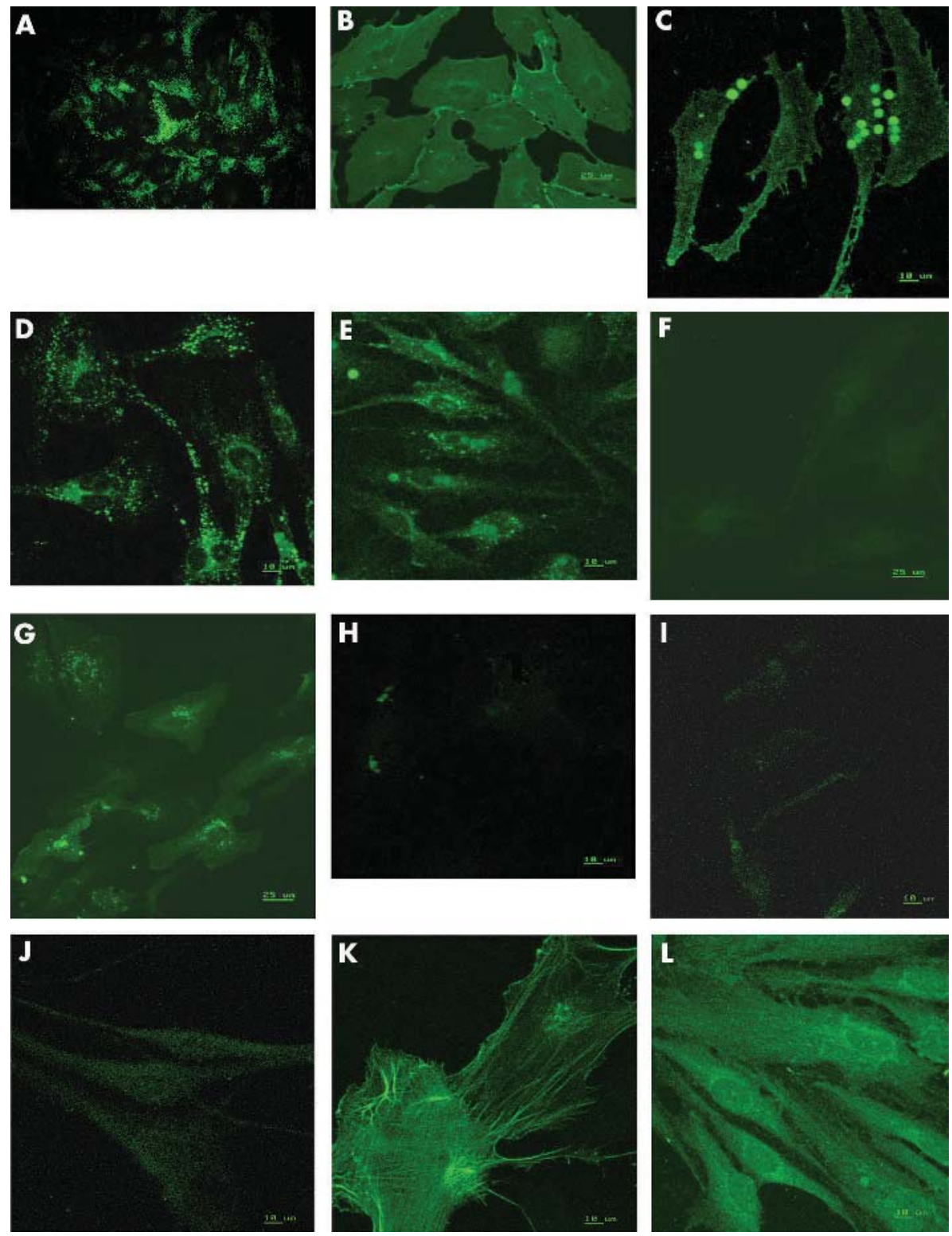

Figure 3 Immunofluorescent photomicrograph of human inner ICECs staining for (A) vWf, (B) CD31, (C) CD 105, (D) VEGF receptor 1, (E) VEGF receptor 2, (F) E-selectin (unstimulated), (G) E-selectin (post-TNF- $\alpha$ stimulation), (H) ) mouse anti-rat isotype negative control, (I) $\alpha$-SMA, (J) fibroblast surface protein, (K) human RPE cells stained for $\alpha$-SMA, (L) human Tenon's capsule fibroblasts stained for fibroblast surface protein. (All $63 \times$ original magnification.)

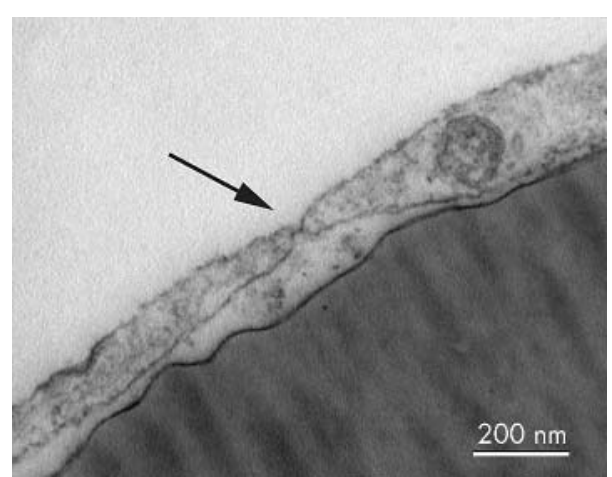

Figure 4 Transmission electron micrograph of human ICECs grown on a collagen IV coated Thermanox coverslip showing a typical fenestration (arrow) (bar $=200 \mathrm{~nm})$.
Fenestrations were found scattered throughout the cells on TEM (fig 4). Cells seeded onto Matrigel formed capillary-like tube structures within 3 hours (fig 5), and TEM showed that these structures possessed a lumen (fig 6) and each lumen was surrounded by up to three cells joined by junctional complexes.

\section{DISCUSSION}

In view of the known heterogeneity of endothelial cells, ${ }^{4-15}$ it would appear logical to study endothelial cells derived from the macular inner choroidal/choriocapillaris area of humans when studying the disease mechanisms of ARMD. While methods have been described for the isolation of human choroidal endothelial cells that contain a mixture of both inner and outer choroidal endothelial cells, ${ }^{23}{ }^{24}$ to date it has not been possible to reliably isolate human macular inner choroidal/choriocapillaris endothelial cells. 


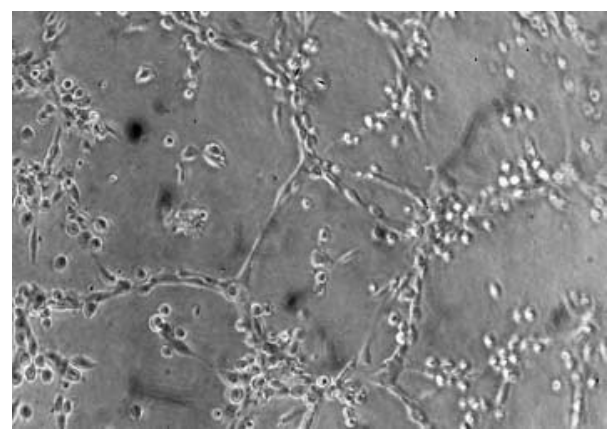

Figure 5 Phase contrast photomicrograph of human ICECs 3 hours after seeding onto Matigel showing typical capillary-like tubes (20x original magnification).

We describe a method to isolate human macular ICECs cells that utilise observations made around 100 years ago. In 1892, Nuel described a natural cleavage plane within the human choroid between the layers of Haller (inner choroid) and Sattler (outer choroid), ${ }^{25}$ while in 1912, Salzmann noted that dissection of the choroid was easiest by teasing apart the layers from the outside. ${ }^{26}$ With the aid of a dissecting microscope and a microdissection technique, we easily peeled the large outer choroidal vessels from the underlying inner choroid/choriocapillaris complex. The subsequent isolation of endothelial cells was achieved using anti-CD31 coated paramagnetic beads. This purification technique replaces the laborious manual method of cell sweeping or the reliance on preferential EC proliferation by using endothelial cell specific culture medium and produces isolates with a purity in excess of $99 \% .^{23} 27-29$

When grown in microvascular endothelial culture medium, the isolated cells formed typical cobblestone patterns consistent with their endothelial cell lineage.

The cells were found to stain strongly for CD31, a ubiquitous endothelial cell marker important in cell-cell adhesion, vWf, VEGF receptors 1 and 2, and CD105. The latter is a subunit of the TGF- $\beta$ receptor found on proliferating vascular endothelial cells and has been suggested as a suitable antigen for antibody directed attack (immunotherapy) on the proliferating endothelial cells within choroidal neovascularisation complexes. ${ }^{30} 31$ The cells also showed expression of E-selectin (CD62E) after stimulation with TNF- $\alpha$, a feature that is reported to be unique to endothelial cells. ${ }^{32}$ There appeared to be no contamination with RPE cells or fibroblasts.

In this study, the isolated cells also formed fenestrations when grown on fibronectin and formed capillary-like tubes when cultured in Matrigel. The lumen of these tubes was surrounded by two or more cells joined by junctional complexes, suggesting that the cells had not simply aggregated together randomly.

In summary, we have developed a method to isolate and culture human ICECs. During early passages, these cells possess the morphological characteristics of vascular endothelial cells, form fenestrations and capillary tube-like structures, and express a number of surface markers consistent with their endothelial cell origin. These cells may be useful in studying the pathophysiology and cellular mechanisms involved in choroidal neovascularisation.

\section{ACKNOWLEDGEMENTS}

We are grateful to the Kelman Foundation, USA, the British Eye Research Foundation (formerly the Iris Fund), and QMC University Hospital Trust for grant funding this project. The authors thank S Anderson and I Ward, School of Biomedical Sciences, University of

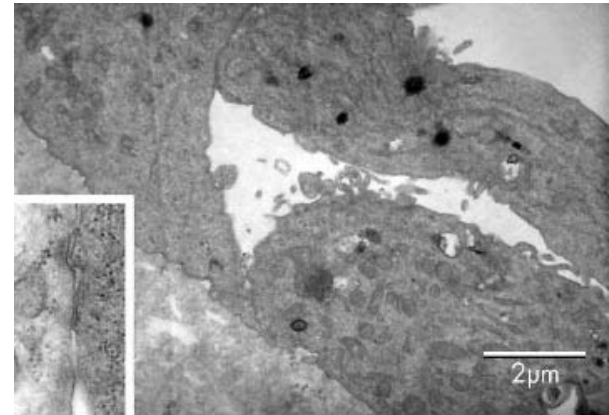

Figure 6 Transmission electron micrograph of a lumen of a capillarylike tube surrounded by ICECs. The cells are joined by tight junctions (higher magnification in inset) and project villi into the lumen (bar $=2 \mu \mathrm{m})$.

Nottingham, for their assistance in conducting the confocal microscopy of the cells and I Zambrano, Eye Bank, Manchester Royal Infirmary, for the provision of the donor eye tissue.

\section{Authors' affiliations}

A C Browning, W M Amoaku, Division of Ophthalmology and Visual Sciences, Eye, Ear, Nose and Throat Centre, University Hospital, Queen's Medical Centre, Nottingham NG7 2UH, UK

T Gray, Division of Histopathology, University Hospital, Queen's Medical Centre, Nottingham NG7 2UH, UK

Competing interests: none declared

Correspondence to: Winfried M Amoaku, Division of Ophthalmology and Visual Sciences, Eye, Ear, Nose and Throat Centre, University Hospital, Queen's Medical Centre, Nottingham NG7 2UH, UK; wma@ nottingham.ac.uk

Accepted for publication 13 May 2005

\section{REFERENCES}

1 Gass JDM. Biomicroscopic and histopathologic considerations regarding the feasibility of surgical excision of subfoveal neovascular membranes. Am J Ophthalmol 1994;118:285-98.

2 Sarks JP, Sarks SH, Killingsworth MC. Morphology of early choroidal neovascularisation in age-related macular degeneration: correlation with activity. Eye 1997;11:515-22.

3 Killingworth MC. Angiogenesis in early choroidal neovascularisation secondary to age-related macular degeneration. Graefes Arch Clin Exp Ophthalmol 1995;233:313-23.

4 Liu X, Ye X, Yanoff M, et al. Regulatory effects of soluble growth factors on choriocapillaris endothelial growth and survival. Ophthalmic Res 1998;30:302-13.

5 Aird WC. Endothelial cell heterogeneity. Crit Care Med 2003;31:S221-S230.

6 Fajardo LF. The complexity of endothelial cells. A review. Am J Clin Pathol 1989;92:241-50.

7 Thorin E, Shreeve SM. Heterogeneity of vascular endothelial cells in normal and disease states. Pharmacol Ther 1998;78:155-66.

8 Rhodin JAG. Ultrastructure of mammalian venous capillaries, venules and small collecting veins. J Ultrastruct Res 1968;25:452-500.

9 Graier WF, Holzmann S, Hoebel BG, et al. Mechanisms of L-NG nitroarginine/indomethacin-restant relaxation in bovine and porcine coronary arteries. Br J Pharmacol 1996; 119:1177-86.

10 Imegwu OJ, Entersz I, Graham AM, et al. Heterotypic smooth muscle cell/ endothelial cell interactions differ between species. J Surg Res 2001;98:85-8.

11 Ram Jl, Hiebert LM. Dextran sulfate protects porcine but not bovine cultured endothelial cells from free radical injury. Can J Vet Med 2003;67:81-7.

12 Lehmann I, Brylla E, Sittig D, et al. Microvascular endothelial cells differ in their basal and tumor necrosis factor-alpha-regulated expression of adhesion molecules and cytokines. J Vasc Res 2000;37:408-16.

13 Craig LE, Spelman JP, Strandberg JD, et al. Endothelial cells from diverse tissues exhibit differences in growth and morphology. Microvasc Res 1998;55:65-76.

14 Muller AM, Hermanns MI, Skrzynski C, et al. Expression of the endothelial markers PECAM-1, vWf, and CD34 in vivo and in vitro. Exp Mol Pathol 2002;72:221-9.

15 Muller AM, Hermanns MI, Cronen C, et al. Comparative study of adhesion molecule expression in cultured human macro- and microvascular endothelial cells. Exp Mol Pathol 2002;73:171-80. 
16 Yang QR, Smets RME, Neetens A, et al. Human retinal pigment epithelial cells from different donors continuously produce a vascular endothelial cell-stimulating factor into serum free medium. J Cell Sc 1993;104:211-18.

17 Sakamoto T, Ishibashi T, Kimura H, et al. Effect of Tecogalan sodium on angiogenesis in vitro by choroidal endothelial cells. Invest Ophthalmol Vis Sci 1995; 36:1076-83.

18 Zubilewicz A, Hecquet C, Jeanny JC, et al. Proliferation of CECs requires dual signaling through both MAPK/ERK and PI 3-k/AKT pathways. Invest Ophthalmol Vis Sci 2001;42:488-96.

19 Liu X, Ye X, Yanoff M, et al. Extracellular matrix of retinal pigment epithelium regulates choriocapillaris endothelial survival in vitro. Exp Eye Res 1997;65:117-26

20 Folkman J, Haudenschild CC, Zetter BR. Long term culture of capillary endothelial cells. Prog Natl Acad Sci 1979;76:5217-21.

21 Robinson G, Gray T. Electron microscopy 2: practical procedures. In Bancroft JD, Stevens A, eds. In:Theory and practice of histological techniques.4th ed. London: Churchill Livingstone, 1996:585-626.

22 Browning AC, Shah S, Dua HS, et al. Alcohol debridement of the corneal epithelium in PRK and LASEK: an electron microscopic study. Invest Ophthalmol Vis Sci 2003;44:510-3.

23 Sakamoto T, Sakamoto H, Hinton DR, et al. In vitro studies of human choroidal endothelial cells. Curr Eye Res 1995;14:621-7.
24 Penfold PL, Wen L, Madigan MC, et al. Modulation of permeability and adhesion molecule expression by human choroidal endothelial cells. Invest Ophthalmol Vis Sci 2002;43:3125-30.

25 Nuel IP. De la vascularisation de la choroide et de la nutrition de la retine principalement au niveau de la fovea centralis. Arch D'Ophtal 1892;12:70-87.

26 Saltzmann $M$. The anatomy and histology of the human eyeball in the normal state. Leipzig, Chicago: Franz Deuticke, 1912:52-63.

27 Silverman MD, Zamora DO, Pan Y, et al. Cell adhesion molecule expression in cultured human iris endothelial cells. Invest Ophthalmol Vis Sci 2001; 42:2861-6.

28 Hull MA, Hewett PW, Brough JL, et al. Isolation and culture of human gastric endothelial cells. Gastroenterology 1996;111:1230-40.

29 Wong HC, Boulton M, Marshall J, etal. Growth of retinal capillary endothelia using pericyte conditioned medium. Invest Ophthalmol Vis Sci 1987;28:1767-75.

30 Duff SE, Li C, Garland JM, et al. CD105 is important for angiogenesis: evidence and potential applications. FASEB J 2003;17:984-992.

31 Yasukawa T, Kimura H, Tabata $\mathrm{Y}$, et al. Active drug targeting with immunoconjugates to choroidal neovascularisation. Curr Eye Res 2000;21:952-61.

32 Bevilacqua MP, Pober JS, Mendrick DL, et al. Identification of an inducible endothelial-leukocyte adhesion molecule. Proc Natl Acad Sci 1987;84:9238-42. 